\title{
Planos diretores municipais e planos de gestão das águas: uma análise comparada das cidades de Lisboa/PT e Porto Alegre/BR
}

Municipal master plans and water management plans: a comparative analysis of the cities of Lisbon/PT and Porto Alegre/BR

Juliana Young ${ }^{[a]}$ (b) , Francisco Manuel Sedoura[b]

[a] Universidade Federal do Pampa (UNIPAMPA), Caçapava do Sul, RS, Brasil

[b] Universidade de Lisboa (ULisboa), Lisboa, Portugal

Como citar: Young, J., \& Sedoura, F. M. (2019). Planos diretores municipais e planos de gestão das águas: uma análise comparada das cidades de Lisboa/PT e Porto Alegre/BR. urbe. Revista Brasileira de Gestão Urbana, 11, e20180001. https://doi.org/10.1590/2175-3369.011.001.A011

\section{Resumo}

A transformação do território está relacionada à ocupação do solo, o que reflete nos recursos hídricos. É necessário que os Planos Diretores Municipais (PDM) contemplem as diretrizes delineadas nos planos de água, levando à transformação sustentável do território e produzindo menos impacto nos rios. 0 objetivo deste trabalho foi analisar a interação entre os planos de água e solo. A inovação aqui apresentada foi o uso das Questões Significativas de Gestão da Água (QSiGA) como ferramenta para comparar os planos diretores das cidades de Lisboa, em Portugal, e de Porto Alegre, no Brasil, localizadas em diferentes realidades. Obteve-se o atendimento de 77,8\% das QSiGA pelo PDM de Lisboa e $61,1 \%$ pelo de Porto Alegre. Ambas as cidades estão preocupadas com a qualidade e a quantidade de água, mas não observam plenamente as diretrizes nacionais. Acredita-se na relevância deste estudo para a materialização de um método de aferição dos PDM que possa ser usado por países com diferentes realidades. Conclui-se que, ao identificar que as diretrizes nacionais não foram totalmente cumpridas, são necessários estudos adicionais para se estabelecer uma metodologia que integre efetivamente planos de água com planos diretores.

Palavras-chave: Água. Gestão. Lisboa. Porto Alegre. Território.

\section{Abstract}

The territory transformation is related to the occupation of the soil, which reflects in the water resources. The Municipal Master Plans (MMP) must contemplate the guidelines outlined in the Water Plans, leading to the sustainable transformation of the territory with less impact on the rivers. This work aimed to analyze the interaction of water and soil plans. The innovation here presented was the use of Significant Water Management Issues (QSiGA) as tool to compare the master plans of the cities of Lisbon-PT and Porto Alegre-BR, located in different realities. The attendance of the QSiGA by the PDM of Lisbon and Porto Alegre was of $77.8 \%$ and $61.1 \%$, respectively. Both cities are concerned about the quality and quantity of water, but do not fully observe the national guidelines. We believe in the relevance of this

JY é geóloga, bacharel em Geologia, mestre em Engenharia, e-mail: julianayoung.unipampa@gmail.com

FMS é arquiteto, licenciado em Arquitetura, doutor em Planejamento Regional e Urbano, e-mail: fs@fa.ulisboa.pt 
study to the materialization of a method of benchmarking the PDM, which can be used by countries with different realities. We conclude that in light of the non-compliance with the national guidelines, additional studies are needed to establish a methodology that integrates effectively water plans with master plans.

Keyword: Water. Management. Lisbon. Porto Alegre. Territory.

\section{Introdução}

Com o decorrer dos anos, a discussão da relação existente entre o binômio sociedade e recursos naturais torna-se mais recorrente, surgindo o questionamento sobre a eficiência da atual forma de gestão dos recursos hídricos, bem como quais seriam os meios para torná-la mais satisfatória e contemporânea no enfrentamento das problemáticas que, porventura, possam surgir devido à ocupação urbana.

Segundo Cordeiro (2014, p. 1-2)

As duas perspectivas - ordenamento do território e gestão dos recursos hídricos - devem articular-se de modo a garantir uma adequada materialização da proteção da água ao nível local.

Diante do exposto, faz-se necessário que os Planos Diretores Municipais (PDM) contemplem as diretrizes observadas nos Planos de Gestão de Região e de Bacia Hidrográfica e no Plano Nacional da Água (PNA), conduzindo a transformação do território em formas ordenadas e sustentáveis de ocupação.

Nesse contexto, os diversos planos constituem uma ferramenta estratégica de gestão - adequados à análise prospectiva -, sendo capazes de auxiliar na tomada de decisão, além de conduzir, de forma eficaz, as mudanças em dado território.

\section{Propósito do trabalho}

O tema proposto converge para temática importante à sociedade: a integração da gestão dos recursos hídricos com o planejamento do uso do solo. Nesse sentido:

[...] É também relevante a existência de instituições competentes e responsáveis por esta articulação. Aspectos como a articulação da política da água com a política de ordenamento do território e de urbanismo, a adoção de legislação e regulamentação sectorial adequada, a cobertura cartográfica do território, a elaboração e atualização da carta administrativa oficial e a gestão do cadastro predial, rústico e urbano do país constituem também ferramentas relevantes para a proteção do território e dos recursos hídricos associados (Afonso, 2016, p. 3).

O objetivo deste trabalho foi analisar a interação entre a gestão das águas com o uso do solo, verificando-se como as diretrizes nacionais são contempladas nos PDM.

Dito isso, criou-se paralelo entre a macrogestão das águas, que é responsável pelo estabelecimento das diretrizes nacionais, com a gestão praticada localmente, a qual está alicerçada nos PDM, principalmente no que tange à pressão da ocupação do território sobre os recursos hídricos.

\section{Desenvolvimento da pesquisa}

A metodologia adotada na pesquisa envolveu a realização de revisão bibliográfica e documental, levantamento de dados por meio de consulta às bases de dados da legislação existente em Portugal e no Brasil, realizando-se direito comparado. Aprofundou-se a pesquisa por meio de estudos de caso, fazendo-se a abordagem quali-quantitativa da informação. 
Desse modo, procedeu-se à leitura interpretativa dos documentos, a qual, conforme Lakatos \& Marconi (2003, p. 23),

[...] é aquela que relaciona as afirmações do autor com os problemas para os quais, através da leitura de textos, está se buscando uma solução.

Propôs-se a utilização das Questões Significativas de Gestão da Água (QSiGA), elencadas no PNA português, como ferramenta para a verificação da incorporação das diretrizes nacionais ao PDM, no concernente às pressões antrópicas.

A identificação das QSiGA está prevista no artigo 14 da Diretiva Quadro da Água da União Europeia (União Europeia, 2000). Essas questões são o resultado do processo participatório de identificação das pressões antropogênicas e seus respectivos impactos sobre as massas de água, que influenciam ou retardam o alcance do seu bom estado.

A determinação das QSiGA é realizada pelo levantamento técnico das pressões, resultando em relatório cuja função é servir como documento base para a discussão pelos stakeholders. Assim, as QSiGA são consideradas fundamentais para o processo de revisão dos Planos de Gestão da Região Hidrográfica (PGRH) pela Agência Portuguesa do Ambiente, pois inserem a participação dos stakeholders na sua identificação, enriquecendo o processo de revisão dos planos diretores de água com múltiplos olhares, além de promover a reflexão entre os envolvidos sobre o custo socioambiental da utilização de certas áreas urbanas, por exemplo, as planícies de inundação.

Neste trabalho, utilizaram-se as QSiGA adotadas pelo PNA de Portugal, fazendo-se adaptações para atender ao caso brasileiro.

Finalmente, pesquisou-se a interação entre os PNA e os PDM, elegendo-se as cidades de Lisboa (Portugal) e de Porto Alegre (Brasil) para os casos de estudo.

Debruçou-se sobre os dois planos diretores, verificando-se cada artigo quanto à sua correspondência ou não com as QSiGA e possibilitando, assim, a comparação.

Para cada tema com equivalência no plano diretor, foi atribuído o valor de 1 unidade. A não correspondência foi considerada nula. Dessa forma, pode-se quantificar o atendimento às 18 temáticas das QSiGA. Realizando-se o tratamento estatístico dos resultados, obteve-se o percentual de atendimento às temáticas, facilitando a comparação entre as duas cidades.

\section{Interação dos regramentos na gestão do solo e da água}

De acordo com Saraiva (1995), água e solo são recursos naturais que sofrem grandes pressões, pois são de utilização essencial de praticamente todos os usos da sociedade, sendo fator limitante do desenvolvimento. Destarte, faz-se necessária a elaboração de modelos integrados de planejamento e de gestão que levem em consideração também a variável ambiental na tomada de decisão.

Ainda, aponta-se que componentes biofísicos e sociais são indissociáveis dos processos de ordenamento dos recursos naturais, sendo ressaltada a importância do planejamento do solo (Saraiva, 1995).

A tendência mundial atual tem sido nortear os regramentos ao gerenciamento integrado dos recursos hídricos. Todavia, é entendimento majoritário de que, planejando-se global ou localmente, a totalidade do território deve ser considerada discorrendo as diversas interações e seus respectivos efeitos em cada escala.

\section{Comparando o quadro legal em Portugal e no Brasil}

As águas em Portugal são consideradas domínio público, o que foi herdado do direito romano, ao classificar as "res humani juris" (Costa et al., 2011). 
Ao longo do tempo, o conceito foi revisto em vários diplomas legais. Por meio do Decreto-lei no 468/71, foi instituída a figura da zona adjacente, considerada como a área contígua à margem de um rio atingida pela maior cheia ocorrida em um século. Essa área fica restrita à utilidade pública devido ao risco de cheia. 0 condicionante, embora criado sob a ótica antropocêntrica, reflete na conservação dos rios, em razão da impossibilidade de uso da faixa de terra.

Entretanto, Teiga (2011, p. 27) alerta que, embora os Planos Diretores Municipais considerem como área não edificável até 10 metros das margens da linha de água

[...] várias exceções na aplicação da norma têm resultado em artificialização dos leitos e margens, provocando prejuízos aos ecossistemas ribeirinhos.

A base jurídica do ordenamento do território está contemplada na Constituição da República Portuguesa (CRP), na qual cabe ao Estado, às regiões autônomas e às autarquias definir as regras de ocupação, uso e transformação dos solos urbanos por meio de instrumentos de planejamento, dando ênfase à utilidade pública urbanística do território (Portugal, 1976).

Essa lei ainda define o direito ao ambiente sadio e ecologicamente equilibrado, incumbindo ao Estado, com o envolvimento dos cidadãos, o ordenamento do território para a correta localização das atividades, com equilibrado desenvolvimento socioeconômico e valorização da paisagem (Portugal, 1976).

Contudo, a Lei de Bases Gerais da Política Pública de Solos, de Ordenamento do Território e de Urbanismo (Lei no 31/2014, de 30 de maio) estabelece o sistema de planejamento territorial português, orientando os municípios para:

(...) valorizar as potencialidades do solo, salvaguardando a sua qualidade e a realização das suas funções ambientais, econômicas, sociais e culturais, enquanto suporte físico e de enquadramento cultural para as pessoas e suas atividades, fonte de matérias-primas e de produção de biomassa, reservatório de carbono e reserva de biodiversidade (Portugal, 2014, art. 2, alínea a).

A Lei no 58/2005, também conhecida como Lei da Água Portuguesa, alterada e republicada pelo Decreto-lei no 130/2012, transpôs para a legislação nacional portuguesa a Diretiva Quadro da Água (DQA) do Parlamento Europeu e do Conselho, referindo ser de incumbência da autoridade nacional da água

Promover a protecção e o planeamento das águas, através da elaboração do Plano Nacional da Água e da aprovação dos planos específicos de gestão de águas e dos planos de gestão de bacia hidrográfica (Portugal, 2005, art. $8^{\circ}$ ).

Essa lei promove o planejamento das águas fundamentando e orientando a proteção e a gestão, para compatibilizar os usos com as suas disponibilidades. Assim, o legislador procura garantir a utilização sustentável, propondo critérios de priorização aos vários tipos de usos pretendidos e adotando normas de qualidade ambiental (APA, 2016).

Ainda por meio dessa lei, no artigo 85, Portugal incorporou a indicação da DQA quanto à elaboração de forma participativa das QSiGA, ou seja, a identificação das pressões impostas pelo homem sobre as massas de água, de forma a encontrar alternativas para sua contenção, sem travar o desenvolvimento da região hidrográfica (Portugal, 2005).

A partir do Código das Águas (Decreto № 2.4643/34), a dominialidade passou a ser também pública no Brasil, proporcionando ao governo legitimidade para controlar e incentivar o aproveitamento industrial delas. Entretanto, esse decreto manteve como águas particulares "as nascentes e todas as águas situadas em terrenos que também o sejam", desde que não estivessem no rol das águas públicas e comuns (Brasil, 1934, art. 8).

A Constituição da República Federativa Brasileira ordenou as atribuições das diversas instâncias de governo, determinando a responsabilidade compartilhada entre União, Estados e municípios a fim de resguardar o meio ambiente e combater a poluição; ainda, de legislar concorrentemente sobre conservação da natureza, defesa do solo e dos recursos naturais, proteção do meio ambiente e controle da poluição. Ademais, define como bens dos Estados as águas superficiais ou subterrâneas, fluentes, emergentes e em depósito, excetuando as decorrentes de obras da União (Brasil, 1988). 
Outrossim, é estabelecida a competência dos municípios:

[...] para legislar sobre assuntos de interesse local; suplementar a legislação federal e a estadual no que couber; bem como, promover o adequado ordenamento territorial, mediante planejamento e controle do uso, do parcelamento e da ocupação do solo urbano (Brasil, 1988, art. 23-30).

Em relação ao ordenamento adotado no Brasil, para Peres \& Silva (2010) o plano diretor deve ter relação com todos os instrumentos:

Do ponto de vista dos municípios, o Estatuto da Cidade instituiu o Plano Diretor em um novo e estratégico patamar: ele é considerado a matriz do desenvolvimento urbano do município, com o qual todos os demais instrumentos de política urbana devem guardar estreita relação (Peres \& Silva, 2010, p. 8).

A Lei Federal no 6.766/79 dispõe sobre o parcelamento do solo urbano, elencando como requisito fundamental a obrigatoriedade de uma

[...] faixa não edificável de 15 metros de cada lado, ao longo das águas correntes e dormentes [...] (Brasil, 1979, art. 4⿳⺈, inciso III).

Contudo, a Lei no 12.727/12, que alterou o Código Florestal Brasileiro, estabelece faixas não edificáveis de 50 metros para áreas no entorno de nascentes e áreas encharcadas (Brasil, 2012).

Por meio da Lei no 9.433/1997, Lei da Água Brasileira, foi estabelecida a Política Nacional de Recursos Hídricos (PNRH), que promove a gestão integrada dos recursos hídricos e indica o planejamento, a regulação e o controle da utilização da água por meio do Plano Nacional de Recursos Hídricos (Brasil, 1997).

O Quadro 1 sintetiza as principais leis com as temáticas abordadas.

Quadro 1 - Regramentos que interferem na relação água e solo

\begin{tabular}{|c|c|c|}
\hline Temática/país & Portugal & Brasil \\
\hline \multirow[b]{2}{*}{$\begin{array}{l}\text { Dominialidade das } \\
\text { águas. }\end{array}$} & Domínio público & Domínio público \\
\hline & $\begin{array}{c}\text { Constituição da República Portuguesa (CRP) (2 de } \\
\text { abril de 1976) (VIl revisão em 2005) (Art. 84). }\end{array}$ & $\begin{array}{c}\text { Constituição Federal/1988 (Art. 20) e Decreto n } \\
\text { 24.643/34 (Art. } 2^{\circ} \text { ). }\end{array}$ \\
\hline Faixa não edificável. & $10 \mathrm{~m}$ (Decreto-lei n 468/71). & $\begin{array}{l}15 \mathrm{~m} \text { (Lei Federal no 6.766/79), 30, 50, } 200 \text { e } 500 \text { m } \\
\text { (Lei Federal } n^{\circ} 12.727 / 12 \text { - Código Florestal). }\end{array}$ \\
\hline $\begin{array}{l}\text { Parcelamento do } \\
\text { solo. }\end{array}$ & Art. 66 da CRP/1976 e Lei n 31/2014. & $\begin{array}{l}\text { Lei Federal } n^{0} 6.766 / 79 \text { e Lei Federal } n^{\circ} 10.257 / 01 \\
\text { (Estatuto das Cidades). }\end{array}$ \\
\hline $\begin{array}{l}\text { Política e gestão da } \\
\text { água. }\end{array}$ & Lei n 58/2005 e Decreto-lei n 130/2012. & Lei Federal n’ 9.433/97. \\
\hline Unidade de gestão. & Região hidrográfica. & Bacia hidrográfica. \\
\hline
\end{tabular}

Fonte: elaborado pelos autores (2018).

Na maioria dos países, a gestão das águas é voltada ao alcance do seu bom estado, regra observada na Europa, de acordo com orientação posta pela DQA, que enseja maior disponibilidade desse recurso para atender aos múltiplos usos. Sob essa ótica, considera-se que a água é um patrimônio a ser protegido e defendido como tal (União Europeia, 2000, art. 4).

\section{Conceitos relacionados à gestão}

Quando se fala em bom estado das águas, convém ter o entendimento sobre o que são sistemas fluviais, os quais, para alcançar o "bom estado", necessitam de condições de equilíbrio de todo o ecossistema.

Para Carvalho (2009, p. 24), os sistemas fluviais são divididos "de acordo com suas funções: paisagísticas, hidráulica, biofísica e econômica". Nesse sentido, 
[...] para a compreensão dos ecossistemas fluviais e sua gestão e recuperação, é necessária esta aproximação holística da realidade ecológica espácio-temporal, considerando as perturbações alóctones como forças disruptivas destas quatro vias de interacções (Carvalho, 2009, p. 25).

Não obstante, citam-se as recomendações feitas pela Comunidade Europeia para que o ordenamento do território "realize a gestão prudente dos recursos hídricos, enfatizando a importância dos rios como corredores ecológicos e o papel fundamental dos sistemas fluviais, fazendo-se necessário o ordenamento das margens e zonas inundáveis" (Moreira et al., 2004, p. 553).

Tendo-se em mente a influência direta do uso e da ocupação do solo sobre os sistemas fluviais, e vice-versa, percebe-se a importância da compatibilização dos diversos planos, sendo imprescindível a existência de mecanismos que direcionem as opções de uso do solo e da água de maneira associada, objetivando a manutenção dos ecossistemas fluviais.

Carter (2007) admite que são poucos os casos em que há uma ligação entre a implementação da DQA e os PDM.

[...] os técnicos da área de planejamento ainda encontram muita resistência quando tentam avançar na direção da gestão sustentável da água, havendo grande dificuldade para elaboração dos planos de água e de ordenamento do território, em função dos diferentes setores e níveis de governo responsáveis (Carter, 2007, p. 341).

No concernente à gestão das águas, Portugal e Brasil apoiam-se em planos. O planejamento de Portugal ocorre em função do domínio, existindo o Plano Nacional da Água, os Planos de Gestão de Região Hidrográfica e os Planos Específicos de Gestão das Águas (APA, 2016).

Da mesma forma, o planejamento brasileiro ocorre por meio do Plano Nacional de Recursos Hídricos, dos Planos Estaduais de Recursos Hídricos e dos Planos de Gestão de Bacia Hidrográfica, sendo elaborados pela Agência Nacional de Águas (ANA), pelos Estados e pelas Agências de Bacia, acompanhados pelos Comitês de Bacia e referendados pelos Conselhos de Recursos Hídricos.

O PNA português é uma estratégia para a gestão integrada, que estabelece a política nacional da água, sinalizando princípios e regras de orientação dessa política, sendo:

[...] orientado por objectivos de natureza sectorial e de incidência transversal nas políticas de outros sectores de actividade, razão pela qual se centra em questões cuja relevância e ou proliferação territorial constituem prioridades de resolução a curto e médio prazos [...] (APA, 2015).

Assim, o referido plano caracteriza-se como um instrumento de planejamento programático e traz a visão estratégica da gestão dos recursos hídricos baseada na lógica de proteção do recurso e de sustentabilidade do desenvolvimento socioeconômico nacional, com horizonte de no máximo dez anos. Sua revisão é prevista a cada oito anos, reforçando a necessidade de compatibilizar com os demais instrumentos de planejamento (Portugal, 2002; Portugal, 2016). Esse plano equivale-se ao Plano Nacional de Recursos Hídricos do Brasil.

Os PGRH são instrumentos de planejamento das águas que buscam a gestão, a proteção e a valorização ambiental, social e econômica das águas, na escala da região hidrográfica. A indicação é de que sejam revistos e atualizados a cada seis anos (APA, 2016). Não há equivalente brasileiro ao PGRH; ele seria uma combinação do Plano Estadual de Recursos Hídricos com todos planos de bacia de determinada região hidrográfica.

De acordo com Mendes:

[...] o ordenamento do território é visto como uma visão e um processo de organização e gestão integrada de um recurso - o território - no qual se pretende organizar as actividades humanas e sua adequação às capacidades e vocações do solo, com o intuito de melhorar as condições de vida do ponto de vista ambiental, social e econômico, que em conjunto constituem os três pilares da sustentabilidade. (Mendes, 2010, p. 5).

Desse modo, os Planos Diretores Municipais (PDM) estabelecem 
[...] a estratégia de desenvolvimento territorial municipal, o modelo territorial municipal, as opções de localização e de gestão de equipamentos de utilização coletiva e as relações de interdependência com os municípios vizinhos (Portugal, 1999, art. 98).

Esses planos são enquadrados na lei de bases gerais da política pública de solos, de ordenamento do território e de urbanismo. A revisão do Plano Diretor Municipal de Lisboa (PDML) é obrigatória e realizada pela Câmara Municipal a cada dez anos, ou sempre que houver modificação do modelo territorial (Portugal, 1999).

No Brasil, a partir da Constituição de 1988 e da Lei no 10.257/2001, conhecida como Estatuto da Cidade, ficou instituída a normativa do planejamento urbano, ao dispor que o PDM deve ser criado por meio de lei municipal aprovada pela Câmara Municipal e revisado a cada dez anos, sendo obrigatório para cidades com mais de 20 mil habitantes ou municípios que integrem a região metropolitana, considerando-o como instrumento básico da política de desenvolvimento e de expansão urbana (Brasil, 1988; Brasil, 2001).

\section{As cidades de Lisboa/PT e de Porto Alegre/BR}

Os casos de estudo contemplaram as cidades de Lisboa e de Porto Alegre, ambas com uma ligação muito forte com as águas que banham seus territórios: o rio Tejo e o Lago Guaíba, respectivamente.

O Quadro 2 permite realizar uma comparação das características dessas cidades.

Quadro 2 - Principais características das cidades Lisboa e de Porto Alegre

\begin{tabular}{|c|c|c|}
\hline $\begin{array}{l}\text { Parâmetro } \\
\text { comparativo }\end{array}$ & Lisboa - Portugal & Porto Alegre - Brasil \\
\hline Municípios vizinhos & Oeiras, Amadora, Odivelas e Loures & $\begin{array}{c}\text { Viamão, Alvorada, Canoas, Cachoeirinha, } \\
\text { Nova Santa Rita, Triunfo, Eldorado do Sul e } \\
\text { Guaíba }\end{array}$ \\
\hline Área & $100,05 \mathrm{~km}^{2}-2.761 \mathrm{~km}^{2}$ (distrito) & $496,68 \mathrm{~km}^{2}$ \\
\hline$N^{0}$ habitantes & 2.821 .876 (distrito) & 1.481 .019 (região metropolitana) \\
\hline $\begin{array}{c}\text { Densidade } \\
\text { demográfica }\end{array}$ & $940 \mathrm{hab} . / \mathrm{km}^{2}$ & $2.981,8 \mathrm{hab} . / \mathrm{km}^{2}$ \\
\hline$\%$ idosos & 18,2 & 15 \\
\hline \% jovens & 15,5 & 29 \\
\hline $\mathrm{PIB}$ & 26.100 euros & 12.416 euros \\
\hline Clima & Mediterrâneo quente e temperado & Subtropical úmido \\
\hline Temperatura média & $16,9^{\circ} \mathrm{C}$ & $19,5^{\circ} \mathrm{C}$ \\
\hline $\begin{array}{c}\text { Classificação } \\
\text { climática de Köppen }\end{array}$ & Csa & Cfa \\
\hline $\begin{array}{l}\text { Pluviosidade média } \\
\text { anual }\end{array}$ & $691 \mathrm{~mm}$ & $1397 \mathrm{~mm}$ \\
\hline $\mathrm{IDH}$ & 0,931 & 0,805 \\
\hline Plano diretor & $\begin{array}{c}\text { PDML - Aviso } n^{\circ} 11622 / 2012 \text {, de } 30 \text { de agosto, aprova revisão } \\
\text { do PDML }\end{array}$ & $\begin{array}{l}\text { PDDUA - Lei Complementar } n^{\circ} 434 / 1999 \\
\text { de } 1 \text { de dezembro }\end{array}$ \\
\hline Fonte de pesquisa & $\begin{array}{l}\text { INE (201 1), Câmara Municipal de Lisboa (2012), Câmara } \\
\text { Municipal de Lisboa (2016), Câmara Municipal de Lisboa } \\
\text { (2017) e Climate-Data.Org (2017) }\end{array}$ & $\begin{array}{l}\text { IBGE (2016), Climate-Data.Org (2017) e } \\
\text { DMAE (2016) }\end{array}$ \\
\hline
\end{tabular}

Fonte: elaborado pelos autores (2018).

\section{A cidade de Lisboa}

Lisboa é a capital de Portugal, e toda a sua história envolve sua posição estratégica, na foz do maior rio da Península Ibérica, o Tejo. Ao longo do tempo, seu desenvolvimento enquanto cidade foi influenciado por diferentes culturas, principalmente pela sua posição geográfica, que facilitava o comércio na foz do rio. 
Essa cidade portuguesa insere-se na região de Lisboa, que se limita ao norte com o distrito de Leiria, a leste com o distrito de Santarém, ao sul com o distrito de Setúbal e a oeste com o Oceano Atlântico. Esse distrito é apontado como o 16º maior distrito português (INE, 2011).

Além de guerras e ocupações, a cidade passou por eventos naturais catastróficos, como o terremoto ocorrido em novembro de 1755, que contribuiu para a transformação radical de Lisboa, descrita pela Câmara Municipal como:

[...] uma cidade de traçado regular e quarteirões uniformes. Da Lisboa barroca ficou apenas a memória de uma cidade mítica, caracterizada pelos viajantes estrangeiros como uma peculiar combinação de extrema devoção religiosa, chocante miséria e desmedida opulência (Câmara Municipal de Lisboa, 2017).

Quanto à infraestrutura de saneamento em Lisboa, a cobertura de redes de água e esgoto pertence à Empresa Portuguesa de Águas Livres (EPAL), responsável pelo abastecimento e tratamento de águas residuais. A coleta dos resíduos produzidos na cidade é de responsabilidade da Direção Municipal de Higiene Urbana, com cobertura de 100\%. Possui um IDH de 0,931, considerado elevado, se comparado ao de Portugal, que é de 0,843 (INE, 2011).

Quanto à caracterização da população, verifica-se uma tendência de redução e envelhecimento com aumento de aglomerações metropolitanas (Câmara Municipal de Lisboa, 2017).

\section{A cidade de Porto Alegre}

0 povoamento da cidade de Porto Alegre começou em 1752, com a chegada de 60 casais portugueses açorianos que se instalaram próximo às águas do Guaíba. A cidade foi fundada em 26 de março de 1772 , com a criação da freguesia de São Francisco do Porto dos Casais, posteriormente chamada Nossa Senhora da Madre de Deus de Porto Alegre. Passou a ser capital do Rio Grande do Sul em 1773, quando começou a receber imigrantes de todo o mundo, especialmente alemães, italianos, espanhóis e poloneses. Em 1835, iniciou-se em Porto Alegre a guerra dos Farrapos, uma revolta do povo local para tornar-se independente do império português. Ao final dessa guerra, a cidade sofreu uma reestruturação urbana com o crescimento de portos e estaleiros.

Apresenta IDH de 0,805, destacando-se em comparação com o do país, que é de 0,754 (IBGE, 2016). Quanto à prestação de serviços básicos, seus níveis de atendimento são superiores em relação a algumas outras capitais, demonstrando condições consideradas satisfatórias nos quesitos energia e abastecimento de água (Balarine, 1996). No que se refere ao saneamento, atualmente $100 \%$ dos portoalegrenses são abastecidos com água tratada e $88 \%$ da população dispõe do serviço de coleta de esgoto, cuja capacidade de tratamento é de $80 \%$ (DMAE, 2016).

A coleta de resíduos sólidos atende a $100 \%$ dos domicílios, e o seu destino final é o aterro sanitário da COPELMI, em Minas do Leão, a 100 quilômetros de distância de Porto Alegre. Há coleta seletiva para os recicláveis, mas não possui 100\% de cobertura (DMLU, 2017).

As ações motivadas pela preocupação com as enchentes iniciaram depois da ocorrida em 1941, quando toda a região central da cidade ficou alagada. Por essa razão, na década de 1960, iniciou-se um grande projeto pelo Departamento Nacional de Obras de Saneamento (DNOS) - hoje extinto -, delineando o sistema de macrodrenagem do município (Porto Alegre, 2015).

\section{O PDM e sua compatibilização com os demais instrumentos de planejamento}

Saraiva (1999, p. 113) coloca que os rios têm se mostrado eixos estruturantes do ordenamento do território, em especial por suas funções de circulação e transporte nas vias navegáveis, abastecimento, recepção de efluentes, geração de energia, entre outros. 


\section{O PDML é}

[...] um instrumento de planejamento territorial, que estabelece o modelo de organização espacial e a estratégia de desenvolvimento do território municipal, a classificação do solo e as regras e parâmetros aplicáveis à ocupação, uso e transformação do solo (Portugal, 2012, p. 30275).

Esse plano levou em consideração fatores socioeconômicos, climáticos, geológicos, arqueológicos, culturais, de mobilidade urbana, entre outros, buscando direcionar o crescimento e/ou a regeneração de áreas consolidadas com base no contexto existente.

A aprovação da revisão do PDML, publicada em 2012, considerou o Programa Nacional da Política de Ordenamento do Território (PNPOT), que define as linhas de orientação estratégica da política territorial para 20 anos. 0 PDML elencou estratégias de desenvolvimento, destacando-se entre elas:

Promover uma cidade ambientalmente sustentável e eficiente na forma como utiliza os recursos, incentivando a utilização de recursos renováveis, uma correta gestão de resíduos, a agricultura urbana e a continuidade dos sistemas naturais e aumentando a resiliência urbana. (Portugal, 2012, art.2, parágrafo $1^{\circ}$, alínea).

O PNA prevê que a gestão da água possua articulação com as políticas setoriais, visto sua natureza fundamental e porque as águas são influenciadas pelas atividades setoriais. Assim, o planejamento em âmbitos nacional e de região hidrográfica necessita de uma visão integrada, que considere a relação da água com os demais setores e as áreas políticas (APA, 2015).

A compatibilização entre o Plano Nacional da Água, o Plano de Gestão de Região Hidrográfica e os Planos Diretores Municipais ocorre por conta de normativa legal, que inicialmente amparou-se na Lei de Bases do Ordenamento do Território (Lei no 48/98, de 11 de agosto) e pela legislação dos instrumentos de planejamento territorial (Decreto-lei no 380/99, de 22 de setembro). Com essas normativas, introduz-se a orientação aos municípios para que contemplem, na nova geração de planos diretores, as diretrizes das demais esferas.

A Lei de Bases, que trata da caracterização dos instrumentos de gestão territorial, determina que o Plano Diretor Municipal, com base na estratégia de desenvolvimento local, deve:

Estabelecer a estrutura espacial, a classificação básica do solo, bem como os parâmetros de ocupação, considerando a implantação dos equipamentos sociais, e desenvolver a qualificação dos solos urbano e rural (Portugal, 1998, art. 9, parágrafo $2^{\circ}$ ).

Essa lei foi revogada pela Lei no $31 / 2014$, de 30 de maio, a qual mantém no artigo 44 o direcionamento à necessidade de adequação sempre que entre em vigor um programa territorial de âmbito nacional ou regional, obrigando a alteração ou a atualização dos planos territoriais de âmbito intermunicipal e municipal, caso não estejam compatíveis com as demais esferas. Com essa lei, que estabelece as bases da política de ordenamento do território e de urbanismo, o sistema de gestão territorial começa a se configurar alicerçado na articulação entre as três escalas de intervenção nacional, regional e municipal. Ainda que impositiva, essa diretriz possibilita planos mais efetivos.

No Brasil, não há norma específica conduzindo a compatibilização dos diversos planos, mas sim uma indicação para observação das demais normas e uma hierarquia entre leis, de modo que uma lei municipal não deva contrariar o exposto em leis estaduais e federais, devendo suplementá-las, sendo mais restritiva, mas nunca oposta. Também a Lei no 9.433/97 indica a necessidade de compatibilização dos diversos planos, porém sem qualquer indicação de como deve ser esse processo.

O primeiro Plano Diretor de Porto Alegre data de 1959. Sua concepção foi alterada em 1979 para Plano Diretor de Desenvolvimento e, em 1999, foi sancionado o Plano de Desenvolvimento Urbano Ambiental (PDDUA), contemplando o viés ambiental e valorizando os saberes locais, por meio do envolvimento da comunidade na sua elaboração. O Conselho Municipal de Desenvolvimento Urbano Ambiental (CMDUA) é o órgão de integração do Sistema Municipal de Gestão do Planejamento (SMGP), responsável pelo processo permanente e sistematizado de atualização do plano. 
O PDDUA incorpora a visão da sustentabilidade ambiental. A implementação da estratégia ambiental foi prevista pela promoção de ações de saneamento, monitoramento da poluição e de otimização do consumo energético, com articulação entre diversos programas, tais como: de implantação e manutenção de áreas verdes urbanas, de gestão ambiental, de prevenção e controle da poluição. Ainda, estabelece bases para a regulamentação da drenagem urbana, identificando zonas problemáticas nas quais devem ser construídos reservatórios de detenção pluvial e ampliadas as redes que se mostraram insuficientes.

Quanto ao parcelamento do solo, estabelece condicionantes do espaço para a drenagem urbana como faixa "não edificável" e define que novos empreendimentos devem manter as condições hidrológicas originais da bacia, por meio de amortecimento da vazão pluvial. Também restringe o parcelamento do solo em terrenos alagadiços e sujeitos à inundação e de condições geológica e/ou hidrologicamente inapropriadas para construções, sem que sejam tomadas as providências para assegurar o escoamento das águas e a proteção contra cheias (Porto Alegre, 1999; Porto Alegre, 2010).

\section{Resultados e discussão}

A análise dos PDM das duas cidades teve maior ênfase no que diz respeito aos sistemas úmidos do PDML e à drenagem urbana do PDDUA, que interferem diretamente na gestão dos recursos hídricos. Os resultados dessa análise foram obtidos pelo levantamento de quesitos relacionados à pressão sobre as massas de águas, considerando-se as medidas relacionadas ao risco de enchentes, à poluição das águas e ao perigo de escassez. Teve-se como ponto de partida as QSiGA identificadas no Plano Nacional da Água de Portugal.

\section{Compatibilização dos planos do âmbito nacional para o municipal}

Alvim et al. (2015) enfatizam que a gestão dos recursos hídricos no Brasil é realizada por bacias hidrográficas, cujo domínio é federal ou estadual. Porém, a gestão urbana é encargo do município. Isso quer dizer que a municipalidade não tem gerência sobre as massas de água, mas decide sobre os usos e a ocupação do solo que refletem diretamente nelas. Um dos problemas gerados pela falta de diálogo municipal com as demais esferas, quanto ao gerenciamento dos recursos hídricos, relaciona-se às áreas de proteção dos mananciais. Cita-se o exemplo da cidade brasileira de São Paulo, cujas políticas públicas federais e estaduais voltadas para a preservação, conservação e recuperação das bacias hidrográficas têm sido pouco efetivas.

Machado (2013 apud Pizella, 2015) acredita que, embora o município não possua atribuição de legislar sobre as águas, tem o dever de aplicar a Política Nacional dos Recursos Hídricos em seu ordenamento territorial.

Em Portugal, essas questões são absorvidas do Plano Nacional da Água pelo Plano Nacional de Ordenamento do Território, e deste pelo Plano Regional de Ordenamento do Território, que irá indicar as diretrizes para os planos municipais. Essa foi a maneira que Portugal encontrou para articular os diversos planos das diferentes esferas de governo ou nível de planejamento. Destarte, o Plano Nacional dita as diretrizes para todo o país, e cada região as adapta às suas especificidades, prescrevendo critérios a serem observados pelos municípios. A lei da água determina que PGRH e PNA sejam articulados com o Programa Nacional da Política de Ordenamento do Território (PNPOT) e prevê o monitoramento para aferição de melhorias alcançadas entre os ciclos dos planos (APA, 2015).

A identificação das Questões Significativas de Gestão da Água é determinada pela DQA e foram incorporadas pelo PNA português. Elas se relacionam, principalmente, com as condições ambientais. Os critérios para sua identificação consideram: os objetivos da legislação nacional e comunitária no 
domínio da água (em particular os objetivos ambientais da DQA), as principais pressões e o conhecimento disponível sobre o estado das massas de água (APA, 2015).

Como forma de avaliar a observância das diretrizes nacionais, utilizaram-se as QSiGA relativas às pressões e aos impactos sobre as massas de água, adaptando-as para que pudessem ser utilizadas em Porto Alegre. Assim, por meio da análise detalhada dos dois Planos Diretores Municipais, identificou-se o seu atendimento dentro da planificação local.

No Quadro 3, estão elencadas as QSiGA adaptadas, bem como a indicação de como elas estão sendo observadas pelos planos diretores estudados de forma a contemplar o seu atendimento.

Quadro 3 - Comparativo do atendimento das QSiGA pelos Planos Diretores Municipais das cidades de Lisboa e de Porto Alegre

\begin{tabular}{|c|c|c|}
\hline \multirow{2}{*}{ QSIGA } & PDML (estimativas 2021) & PDDUA (estimativas 2035) \\
\hline & Atendimento no PDML & Atendimento no PDDUA \\
\hline 1 Afluências (de outro país, Estado ou município). & $\begin{array}{l}\text { Gestão compartilhada } \\
\text { (não está prevista no PDM). }\end{array}$ & $\begin{array}{l}\text { Gestão compartilhada dos rios } \\
\text { intermunicipais (Gravataí, Sinos, Caí e } \\
\text { Jacuí) (não está prevista no PDM). }\end{array}$ \\
\hline $\begin{array}{c}2 \text { Agravamento da qualidade da água por transporte } \\
\text { de sedimentos. }\end{array}$ & Art. $13, \S 3^{\circ}$. & Art. 18, incisos V e VI. \\
\hline \multirow{2}{*}{$\begin{array}{l}3 \text { Implantação insuficiente ou ineficiente do regime de } \\
\text { caudal ecológico (causa perda de ecossistemas e } \\
\text { concentração da polvição). }\end{array}$} & \multirow[b]{2}{*}{ Art. $13, \S 4^{\circ}$. } & PDM não contempla. \\
\hline & & $\begin{array}{l}\text { Q ecológica é estabelecida pelos } \\
\text { planos de bacia hidrográfica. }\end{array}$ \\
\hline $\begin{array}{l}4 \text { Alteração das comunidades da flora e da fauna ou } \\
\text { redução da biodiversidade. }\end{array}$ & $\begin{array}{l}{\text { Art. } 2^{\circ} \text { (alínea d); Art. 11, }}_{1 \%} \text {; Art. 14; Art. 15, } 1^{\circ} ; \\
\text { Art. } 51, \S 1^{\circ} \text {. }\end{array}$ & $\begin{array}{c}\text { Art. } 88, \S 5^{\circ} \text { (corredores ecológicos) } \\
\text { (incluído pela L.C. } n^{\circ} 646 \text {, de } 22 \text { de julho } \\
\text { de 2010). }\end{array}$ \\
\hline $\begin{array}{c}5 \text { Alteração da dinâmica sedimentar (erosão } \\
\text { assoreamento). }\end{array}$ & $\begin{array}{l}\text { Art. } 7^{\circ} ; \text { Art. } 13, \S 3^{\circ} \text { a } 5^{\circ} ; \\
\text { Art. 19; Art. } 23 .\end{array}$ & $\begin{array}{l}\text { Art. 96, } \S 3^{\circ} \text { (alterado pela L.C. } n^{\circ} 646 \\
\text { de } 22 \text { de julho de } 2010 \text { ). }\end{array}$ \\
\hline 6 Alterações do regime de escoamento. & $\begin{array}{c}\text { Art. 19, } \S 1^{\circ} \text { e } 2^{\circ} ; \text { Art. } 13 \\
\S 3^{\circ} \text { a } 7^{\circ}\end{array}$ & Art. 96, § 11; Art. 97. \\
\hline $\begin{array}{c}7 \text { Competição de espécies não nativas com } \\
\text { autóctones. }\end{array}$ & $\begin{array}{c}\text { Considerada insignificante } \\
\text { na RH5 } \\
\text { (não contemplada). }\end{array}$ & Não contemplada. \\
\hline 8 Contaminação de água subterrânea. & Art. 25; Art. 81 (alínea j). & Art. 17; Art. 18. \\
\hline $\begin{array}{l}9 \text { Degradação de zonas costeiras (adaptado para } \\
\text { degradação de banhados, nascentes etc.). }\end{array}$ & $\begin{array}{l}\text { Considerada insignificante } \\
\text { na RH5 (não } \\
\text { contemplada). } \\
\end{array}$ & Art. $96, \S 3^{\circ}$. \\
\hline 10 Destruição/fragmentação de habitats. & Art. 12 e Art. $15, \S 1^{\circ}$ & Art. 15. \\
\hline 11 Escassez de água. & $\begin{array}{l}\text { Art. 19, § } 4^{\circ} ; \text { Art. } 20 \\
\text { (alínea f). }\end{array}$ & Não contemplada. \\
\hline 12 Eutrofização (Ni, Ph etc.). & Art. 19, § 30; Art. 36. & Art. 18. \\
\hline 13 Intrusão salina (adaptado rebaixamento do freático). & Art. $13, \S 1^{\circ}$ a $3^{\circ} ;$ Art. 22. & Não contemplada. \\
\hline 14 Inundações. & Art. 22; Art. 81 (alínea i). & $\begin{array}{l}\text { Art. 97; Art. } 136 \text { (alterado pela L.C. } \\
n^{0} 646 \text {, de } 22 \text { de julho de 2010). }\end{array}$ \\
\hline 15 Polvição com substâncias prioritárias e perigosas. & $\begin{array}{c}\text { Art. } 2^{\circ}, \S 1^{\circ} \text { (alínea d); Art. } \\
25 \S 1^{\circ} .\end{array}$ & $\begin{array}{l}\text { Art. 18; Art. } 136 \text { (alterado pela L.C. } \\
n^{0} 646 \text {, de } 22 \text { de julho de 2010). }\end{array}$ \\
\hline 16 Polvição microbiológica e orgânica. & Art. $11, \S 5^{\circ}$ & Art. $18, \mathrm{~V} \mathrm{e} \mathrm{VI.}$ \\
\hline 17 Sobre-exploração de águas subterrâneas. & Art. $13, \S 6^{\circ}$. & Não contemplado. \\
\hline 18 Perdas de água no sistema de abastecimento. & $\begin{array}{l}\text { Meta de } 20 \% \text { perda } \\
\text { máxima (não } \\
\text { contemplada). }\end{array}$ & $\begin{array}{l}\text { Perdas de } 24,63 \% \text { (Porto Alegre, 2015) } \\
\text { (não contempladas). }\end{array}$ \\
\hline
\end{tabular}

Fonte: elaborado pelos autores com base em Lisboa (2014), Porto Alegre (2010) e Agência Portuguesa do Ambiente (APA, 2015).

Com base na análise dos resultados, sintetizados no Quadro 1, fez-se a comparação entre as duas cidades em relação ao atendimento ou não das Questões Significativas de Gestão da Água. Na Figura 1, observa-se o percentual de atendimento de cada cidade quanto aos 18 itens das QSiGA. 


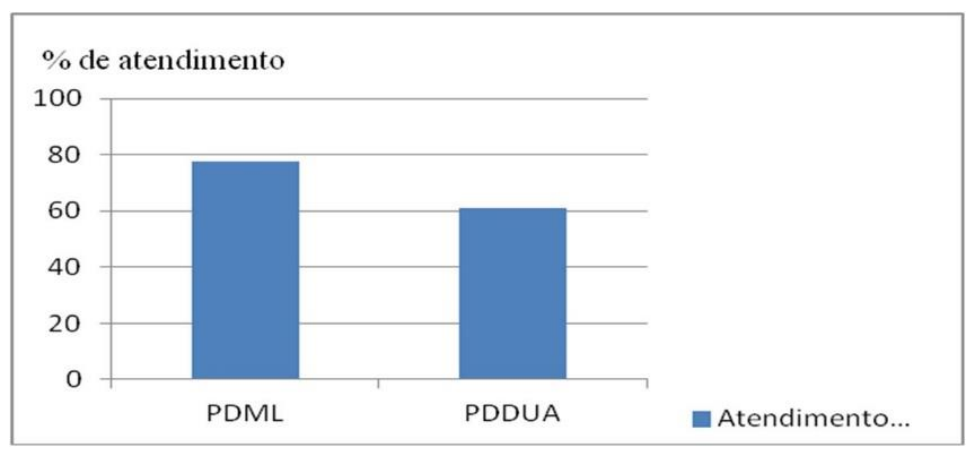

Figura 1 - Percentual de atendimento das QSiGA pelos Planos Diretores Municipais. Fonte: elaborada pelos autores (2018).

No resultado dessa análise, obteve-se o percentual de observância das diretrizes do PNA, considerando-se as propostas assumidas nos PDM, cujas diretrizes, em âmbito local, faziam referência ao Plano Nacional, sendo refletidas nas QSiGA, no que concerne às pressões e aos impactos sobre as massas de água. Obteve-se o resultado de $77,8 \%$ de atendimento das QSiGA pelo PDML, enquanto o PDDUA atendeu a $61,1 \%$.

As duas cidades mostraram percentuais de atendimento acima de $50 \%$, o que não se esperaria para a cidade brasileira. Provavelmente esse resultado deva-se à condição diferenciada da região Sul no que tange à cobertura de saneamento, em comparação a outras capitais brasileiras.

Presumia-se um percentual de atendimento maior para Lisboa, tendo em vista que em Portugal a compatibilização dos diversos planos está prevista na legislação.

Os temas recorrentes nos PDM analisados dizem respeito às diretrizes gerais de proteção e conservação dos corpos de água para utilização em atividades de lazer. Também foi frequente a preocupação com a criação de áreas verdes, o tratamento de esgotos, a previsão adequada de resíduos sólidos, a proteção de áreas alagadas e o controle de inundações. Em menor escala, encontram-se a educação ambiental e a proteção dos recursos hídricos subterrâneos, embora estes estejam indiretamente contemplados pelas políticas de redução de áreas impermeáveis nos centros urbanos.

Percebe-se que ambas as cidades estudadas têm forte preocupação com a salubridade das águas, o que impulsiona o atendimento das QSiGA. Isso pode espelhar a relação que seus habitantes têm com o rio/lago enquanto elemento integrado à paisagem cotidiana.

\section{Conclusão}

O planejamento da gestão dos recursos hídricos deve, sem dúvida, considerar o ordenamento do solo como ferramenta importante para manter e restaurar os cursos de água. Portanto, ao planejar a ocupação do solo, devem ser considerados os usos pretendidos para os recursos hídricos naquela bacia, de forma a não os inviabilizar.

A compatibilização dos diversos planos torna-se cada vez mais necessária para alcançar-se a eficiência a um menor custo, otimizando os diagnósticos e priorizando ações que coincidam com as aspirações da população da bacia.

De acordo com Peres \& Silva (2010, p. 2),

[...] o que se observa no Brasil é a desarticulação entre esses instrumentos, refletindo uma deslegitimação do planejamento e da legislação urbanística nas cidades brasileiras, marcados pela ilegalidade e informalidade da ocupação do solo.

Ainda, esses mesmos autores, analisando o caso da bacia do Tiete-Jacaré, em São Paulo, assinalam que o Plano de Bacia define ações e metas relacionadas à competência municipal, apontando o plano diretor como principal instrumento regulador dessas ações, mas criticam: 
[...] no que se refere aos aspectos de uso e ocupação do solo, o Plano contempla uma análise superficial e incompleta. Em relação aos Planos Diretores Municipais, a análise não é nem sequer realizada, remetendo à necessidade de estudos posteriores sobre este tema. Verifica-se aí uma importante lacuna, a ser estudada e amplamente discutida numa próxima etapa de revisão deste Plano de Bacia (Peres \& Silva, 2010, p.8).

Provavelmente, a falha apontada por esses autores seja um dos motivos para a falta de compatibilização entre planos diretores e planos de água.

Em Lisboa, a interface entre Planos Diretores Municipais e Planos Nacionais foi obtida por diploma legal que obriga a contemplar as diretrizes nacionais nos Planos Locais, o que, aparentemente, tem dado resultados.

No caso de Porto Alegre, ou, de forma mais ampla, para as cidades brasileiras, sugere-se a obrigatoriedade da participação do setor de planejamento urbano municipal em Comitês de Bacia, como membro titular nessas instâncias colegiadas, permitindo-se, assim, incorporar o olhar do planejamento urbano na elaboração dos Planos de Bacia, e vice-versa.

Entende-se que o PDM, sendo um dos principais instrumentos da gestão urbana, tem alto potencial para contribuir para a preservação dos recursos hídricos, desde que estejam calcados no desenvolvimento de cidades mais orgânicas, que respeitem as fragilidades ambientais na ocupação do solo. No contexto atual, é impensável planejar o crescimento de uma cidade sem considerar as questões sociais e ambientais de forma associada, diretriz que deve ser ampliada também aos recursos hídricos.

Ainda há um longo caminho a ser trilhado até que sejam previstas estratégias que minimizem os efeitos negativos da pressão urbana sobre as massas de água. 0 desafio do diálogo entre a gestão da água e a gestão urbana é um processo de legitimação das políticas públicas e amadurecimento da legislação e dos atores sociais.

\section{Referências}

Afonso, M. C. N. (2016). Planeamento dos recursos hídricos e ordenamento do território em São Tomé e Príncipe região autónoma do Príncipe (Dissertação de Mestrado). Faculdade de Ciências e Tecnologia, Universidade Nova de Lisboa, Lisboa, Portugal.

Agência Portuguesa do Ambiente - APA. (2015). Plano nacional da água. Amadora: APA. Recuperado em 25 de abril de 2017, de

https://www.apambiente.pt/_zdata/Politicas/Agua/PlaneamentoeGestao/PNA/2015/PNA2015.pdf

Agência Portuguesa do Ambiente - APA (2016). Plano de gestão de região hidrográfica Tejo e Ribeira do Oeste (RH5) 2016-2021. Parte 1, Enquadramento e Aspectos Gerais. Amadora: APA. Recuperado em 13 de abril de 2017, de https://www.apambiente.pt/_zdata/Politicas/Agua/PlaneamentoeGestao/PGRH/2016-

2021/PTRH5A/PGRH5A_Parte1.pdf

Alvim, A. T. B., Kato, V. R. C., \& Rosin, J. R. G. (2015). A urgência das águas: Intervenções urbanas em áreas de mananciais. Cadernos Metrópole, 17(33), 83-107. http://dx.doi.org/10.1590/2236-9996.2015-3304.

Balarine, O. F. O. (1996). Determinação do impacto de fatores sócio-econômicos na formação do estoque habitacional em Porto Alegre. Porto Alegre: EDIPUCRS.

Brasil. (1934, 10 de julho). Decreto n.o 24.643, de de 10 de julho de 1934. Decreta o código de águas. Rio de Janeiro: Diário Oficial da República Federativa do Brasil. Recuperado em 12 de abril de 2017, de https://www.planalto.gov.br/ccivil_03/decreto/d24643.htm

Brasil. (1979, 19 de dezembro). Lei ${ }^{\circ} 6766$ de 19 de dezembro de 1979. Dispõe sobre o Parcelamento do Solo Urbano e dá outras Providências. Brasilia: Diário Oficial da República Federativa do Brasil. Recuperado em 20 de abril de 2017, de http://www.planalto.gov.br/ccivil_03/leis/L6766.htm 
Brasil. (1988, 05 de outubro). Constituição da República Federativa do Brasil. Brasilia: Diário Oficial da República Federativa do Brasil. Recuperado em 12 de abril de 2017, de http://www.planalto.gov.br/ccivil_03/constituicao/ConstituicaoCompilado.htm

Brasil. (1997, 08 de janeiro). Lei $n^{\circ} 9.433$ de 8 de janeiro de 1997. Institui a Política Nacional de Recursos Hídricos e cria o Sistema Nacional de Gerenciamento de Recursos Hídricos. Brasilia: Diário Oficial da República Federativa do Brasil. Recuperado em 12 de abril de 2017, de http://www.planalto.gov.br/ccivil_03/LEIS/L9433.htm

Brasil. (2001, 10 de julho). Lei $n^{\circ} 10.257$ de 10 de julho de 2001. Regulamenta os arts. 182 e 183 da Constituição Federal, estabelece diretrizes gerais da política urbana e dá outras providências. Brasilia: Diário Oficial da República Federativa do Brasil. Recuperado em 04 de maio de 2017, de http://www.planalto.gov.br/ccivil_03/leis/LEIS_2001/L10257.htm

Brasil. (2012, 17 de outubro). Lei $n^{\circ} 12.727$ de 17 de outubro de 2012. Altera a Lei no 12.651, de 25 de maio de 2012, que dispõe sobre a proteção da vegetação nativa e altera outras leis. Brasilia: Diário Oficial da República Federativa do Brasil. Recuperado em 20 de abril de 2017, de http://www.planalto.gov.br/ccivil_03/_ato20112014/2012/lei/l12727.htm

Câmara Municipal de Lisboa. (2012). Retrato de Lisboa: Pordata / Indicadores 2011. Lisboa: Fundação Francisco Manuel dos Santos. Recuperado em 10 de maio de 2017, de http://www.cmlisboa.pt/investir/investimento/lisboa-em-numeros/retrato-de-lisboa

Câmara Municipal de Lisboa. (2016). Lisboa \%: a economia em números. Lisboa. Recuperado em 10 de maio de 2017,de https://issuu.com/camara_municipal_lisboa/docs/economia_lisboa_numeros_2016_pt_issCâmara Municipal de Lisboa (2017). Sítio Eletrônico da Câmara Municipal de Lisboa. Lisboa. Recuperado em 20 de abril de 2017, de http://www.cm-lisboa.pt

Carter, J. G. (2007). Spatial planning, water and the water framework directive: insights from theory and practice. The Geographical Journal, 173(4), 330-342. http://dx.doi.org/10.1111/j.1475-4959.2007.00257.x.

Carvalho, L. M. A. C. (2009). A importância do rio na cidade - análise do risco de inundação no perímetro urbano da cidade de Leiria (Dissertação de Mestrado). Faculdade de Ciências e Tecnologia, Universidade Nova de Lisboa, Portugal.

Climate-Data.org. (2017). Dados climáticos para cidades mundiais. Recuperado em 04 de maio de 2017, de https://pt.climate-data.org

Cordeiro, A. C. S. (2014). Os recursos hídricos no planeamento territorial ao nível local (Dissertação de Mestrado). Departamento de Ambiente e Ordenamento, Universidade de Aveiro, Portugal.

Costa, F. S., Nossa, P. N. M. S., Magalhães, S. C. M., \& Magalhães, M. A. (2011). A legislação dos recursos hídricos em Portugal e no Brasil: Uma análise histórica comparativa. Recuperado em 12 de abril de 2017, de http://hdl.handle.net/1822/22593

Departamento Municipal de Água e Esgotos - DMAE (2016). Relatório de dados gerais. Porto Alegre: DMAE. Recuperado em 19 de abril de 2017, de http://lproweb.procempa.com.br/pmpa/prefpoa/dmae/usu_doc/relatorio_dados_gerais_2016.pdf

Departamento Municipal de Limpeza Urbana - DMLU (2017). Site oficial DMLU. Porto Alegre. Recuperado em 19 de abril de 2017, de http://www2.portoalegre.rs.gov.br/dmlu/

Instituto Brasileiro de Geografia e Estatística - IBGE (2016). Cidades. Rio de Janeiro: IBGE. Recuperado em 19 de abril de 2017, de http://cod.ibge.gov.br/2L5

Instituto Nacional de Estatística - INE. (2011). Censos 2011: Resultados definitivos Região Lisboa. Lisboa: INE. Recuperado em 19 de abril de 2017, de http://censos.ine.pt/xportal/xmain?xpgid=censos2011_apresentacao\&xpid=CENSOS

Lakatos, E. M., \& Marconi, M. A. (2003). Fundamentos de metodologia científica (5. ed.). São Paulo: Atlas. 
Lisboa. (2014, 08 de maio) Aviso nº5804/2014. Torna pública a aprovação da alteração simplificada do Plano Diretor Municipal de Lisboa. Lisboa: Diario da Republica, $2^{\mathrm{a}}$ serie, no 88, p. 12064. Recuperado em 17 de abril de 2017, de https://dre.tretas.org/dre/316914/aviso-5804-2014-de-8-de-maio

Mendes, M. (2010). Estruturas ecológicas municipais no quadro do ordenamento do território: Uma visão estratégica para o município de Cantanhede (Dissertação de Mestrado). Faculdade de Ciências e Tecnologia, Universidade Nova de Lisboa, Lisboa.

Moreira, I., Saraiva, M. G., \& Correia, F. N. (2004). Gestão ambiental dos sistemas fluviais: Aplicação à bacia hidrográfica do rio Sado. Portugal: ISAPress.

Peres, R. B., \& Silva, R. S. (2010). A relação entre planos de bacia hidrográfica e planos diretores municipais: análise de conflitos e interlocuções visando políticas públicas integradas. In: Anais do V Encontro Nacional da ANPPAS (pp. 1-20). Florianópolis: ANPPAS.

Pizella, D. G. (2015). A relação entre planos diretores municipais e planos de bacias hidrográficas na gestão hídrica. Revista Ambiente \& Água, 10(3), 635-645. http://dx.doi.org/10.4136/ambi-agua.1394.

Porto Alegre. Prefeitura Municipal. (1999, 01 de dezembro). Lei Complementar $n^{\circ}$ 434, de 1o de dezembro de 1999. Plano Diretor de Desenvolvimento Urbano e Ambiental - PDDUA. Recuperado em 25 de abril de 2017, de http://lproweb.procempa.com.br/pmpa/prefpoa/spm/usu_doc/planodiretortexto.pdf

Porto Alegre. Prefeitura Municipal. (2010, 22 de julho). Lei Complementar $n^{\circ} 646$ de 22 de julho de 2010. Altera e inclui dispositivos, figuras e anexos na Lei Complementar no 434, de 1o de dezembro de 1999 (Plano Diretor de Desenvolvimento Urbano Ambiental de Porto Alegre - PDDUA) e dá outras providências. Recuperado em 25 de abril de 2017, de http://www2.portoalegre.rs.gov.br/netahtml/sirel/atos/646\%20rep-PDDUA

Porto Alegre. Prefeitura Municipal. (2015). Plano municipal de saneamento básico - diagnóstico (Vol. 1).

Recuperado em 04 de maio de 2017, de

http://lproweb.procempa.com.br/pmpa/prefpoa/dmae/usu_doc/01_pmsb_diagnostico_web.pdf

Portugal. (1976, 12 de agosto). Constituição da República Portuguesa. Sétima Revisão Constitucional. Lisboa: Diário da República, no 155, I Série A. Recuperado em 17 de abril de 2017, de https://www.parlamento.pt/ArquivoDocumentacao/Documents/CRPVIIrevisao.pdf

Portugal. (1998, 11 de agosto). Lei ${ }^{\circ} 48$ de 11 de Agosto. Estabelece as bases da política de ordenamento do território e de urbanismo. Lisboa: Diário da República, no 184, Série I-A. Recuperado em 14 de abril de 2017, de http://www.pgdlisboa.pt/leis/lei_mostra_articulado.php?nid=1198\&tabela=leis

Portugal. (1999, 22 de setembro). Decreto Lei $n^{\circ} 380$ de 22 de Setembro. Estabelece o regime jurídico dos instrumentos de gestão territorial. Lisboa: Diário da República, no 222, Série I-A. Recuperado em 04 de maio de 2017, de http://data.dre.pt/eli/dec-lei/380/1999/09/22/p/dre/pt/html

Portugal. (2002, 17 de abril). Decreto Lei . $^{\circ} 112$ de 17 de Abril. Aprova o Plano Nacional da Água. Lisboa: Diário da República, I Série-A, n 90. Recuperado em 09 de maio de 2017, de https://dre.pt/application/file/291736

Portugal. (2005, 29 de dezembro) Lei no 58/2005 de 29 de Dezembro. Aprova a Lei da Água, transpondo para a ordem jurídica nacional a Directiva n. ${ }^{\circ}$ 2000/60/CE, do Parlamento Europeu e do Conselho, de 23 de Outubro, e estabelecendo as bases e o quadro institucional para a gestão sustentável das águas. Lisboa: Diário da República. Recuperado em: 17 de abril de 2017, de

http://www.pgdlisboa.pt/leis/lei_mostra_estrutura.php?tabela=leis\&artigo_id=\&nid=1191\&nversao=\&tabela=leis \&so_miolo=

Portugal. (2012, 30 de agosto). Aviso n. ${ }^{\circ}$ 11622/2012 de 30 de agosto. Aprova a Revisão do Plano Diretor Municipal de Lisboa, incluindo o Regulamento, a Planta de Ordenamento e a Planta de Condicionantes. Lisboa: Diário da República, 2ª série, n.o 168. Recuperado em 18 de abril de 2017, de https://dre.pt/application/conteudo/1787349

Portugal. (2014, 30 de maio). Lei n. ${ }^{\circ} 31$ de 30 de maio. Lei de bases gerais da política pública de solos, de ordenamento do território e de urbanismo. Lisboa: Diário da República, $1^{\mathrm{a}}$ série, n.ำ 104 . Recuperado em 14 de abril de 2017, de https://dre.pt/application/conteudo/25345938 
Portugal. (2016, 9 de novembro). Decreto-Lei n. 76 de 9 de novembro. Aprova o Plano Nacional da Água. Lisboa: Diário da República, 1aㅗ série, no2 215. Recuperado em 13 de abril de 2017, de https://dre.pt/application/conteudo/75701996

Saraiva, M. G. A. N. (1995). Gestão de corredores fluviais: o rio como paisagem no quadro do ordenamento do território (Tese de Doutorado). Instituto de Agronomia, Universidade Técnica de Lisboa, Lisboa, Portugal.

Saraiva, M. G. A. N. (1999). O rio como paisagem: gestão de corredores fluviais no quadro do ordenamento do território. Portugal: Ministério da Ciência e Tecnologia.

Teiga, P. M. (2011). Avaliação e mitigação de impactes em reabilitação de rios e ribeiras em zonas edificadas: uma abordagem participativa (Tese de Doutorado). Faculdade de Engenharia, Universidade do Porto, Portugal.

União Europeia. (2000, 23 de outubro). Directiva quadro da água 2000/60/CE de 23 de Outubro de 2000. Estabelece um quadro de ação comunitária no domínio da política da água. Bruxelas: Jornal Oficial das Comunidades Europeias. Recuperado em 18 de abril de 2017, de https://www.apambiente.pt/dqa/assets/01-2000_60_ce--directiva-quadro-da-\%C3\%A1gua.pdf

Editor: Harry Bollmann

Recebido: Jan. 2, 2018

Aprovado: Jul. 15, 2018 